\title{
Glomerular filtration rate estimation in patients with type 2 diabetes: creatinine- or cystatin $\mathbf{C}$-based equations?
}

\author{
F. Iliadis • T. Didangelos • A. Ntemka • A. Makedou • \\ E. Moralidis - A. Gotzamani-Psarakou • \\ T. Kouloukourgiotou • D. Grekas
}

Received: 8 June 2011 / Accepted: 16 August 2011 /Published online: 23 September 2011

(C) Springer-Verlag 2011

\begin{abstract}
Aims/hypothesis It is argued that GFR estimation (eGFR) using cystatin C-based equations (eGFRcys) is superior to that using creatinine-based equations (eGFRcre). We investigated whether eGFRcys are superior to eGFRcre in patients with type 2 diabetes.

Methods GFR was measured in 448 type 2 diabetic patients using ${ }^{51} \mathrm{Cr}$-EDTA-measured GFR (mGFR) as the reference standard. Bias, precision and accuracy of eGFRcys and eGFRcre were compared.

Results The most accurate eGFRcre equation (Chronic Kidney Disease Epidemiology Collaboration [CKD-EPI]), which produced the highest proportion of estimates that were within $30 \%$ and $10 \%$ of the reference standard $(80.7 \%$ and $38.0 \%$ of samples, respectively) had a bias of 7.1 and precision of $12.0 \mathrm{ml} \mathrm{min}^{-1} 1.73 \mathrm{~m}^{-2}$. The calibrated
\end{abstract}

Electronic supplementary material The online version of this article (doi:10.1007/s00125-011-2307-1) contains peer-reviewed but unedited supplementary material, which is available to authorised users.

F. Iliadis $(\bowtie) \cdot$ T. Didangelos $\cdot$ A. Ntemka

T. Kouloukourgiotou $\cdot$ D. Grekas

First Propedeutic Department of Internal Medicine,

University General Hospital AHEPA,

S. Kyriakidi Street 1,

54636 Thessaloniki, Greece

e-mail: iliadis@med.auth.gr

A. Makedou

Laboratory of Lipids, Second Paediatric Department,

AHEPA Hospital, Aristotle University of Thessaloniki,

Thessaloniki, Greece

E. Moralidis $\cdot$ A. Gotzamani-Psarakou

Department of Nuclear Medicine, AHEPA Hospital,

Aristotle University of Thessaloniki,

Thessaloniki, Greece
eGFRcys with the highest accuracy (Tan-C), which produced the highest proportion of estimates that were within $30 \%(78.8 \%)$ and within $10 \%(39.0 \%)$ of the reference standard had a bias of -3.5 and precision of $18.0 \mathrm{ml} \mathrm{min}^{-1}$ $1.73 \mathrm{~m}^{-2}$. Moreover, the areas under the receiver operating curve were higher with eGFRcre (CKD-EPI and Modification of Diet in Renal Disease [MDRD]) than with eGFRcys for the diagnosis of mild (mGFR $<90 \mathrm{ml} \mathrm{min}^{-1} 1.73 \mathrm{~m}^{-2}$ ) and moderate (mGFR $<60 \mathrm{ml} \mathrm{min}{ }^{-1} 1.73 \mathrm{~m}^{-2}$ ) chronic kidney disease. In patients with $\mathrm{mGFR} \geq 90 \mathrm{ml} \mathrm{m^{-1 }} 1.73 \mathrm{~m}^{-2}$, CKD-EPI was the least biased, the most precise and the most accurate equation.

Conclusions/interpretation In patients with type 2 diabetes, eGFRcys do not currently provide better eGFR than eGFRcre. At present, compared with eGFRcys, eGFRcre are better at predicting the stage of chronic kidney disease. In addition, CKD-EPI seems to be the best equation for eGFR in patients with normal renal function.

Keywords Cystatin C. Glomerular filtration rate $\cdot$ Type 2 diabetes
Abbreviations
CKD-EPI Chronic Kidney Disease Epidemiology
Collaboration
eGFR GFR estimation
eGFRcre Creatinine-based equations for
GFR estimation
eGFRcys Cystatin C-based equations for
GFR estimation
IDMS Isotope dilution mass spectrometry
MDRD Modification of Diet in Renal Disease
mGFR $\quad{ }^{51}$ Cr-EDTA-measured GFR
PETIA Particle-enhanced turbidimetric immunoassay 


\section{Introduction}

Diabetes mellitus is the leading cause of end-stage renal disease worldwide [1]. Moreover, diabetic patients, especially those with impaired renal function, are at increased risk of cardiovascular events [2]. In addition, the choice of drugs for treating patients with type 2 diabetes is influenced by GFR. Therefore, routine GFR estimation (eGFR) is strongly recommended for patients with diabetes mellitus [3]. The 'gold standard' for GFR measurement is the renal clearance of inulin, while the plasma disappearance or clearance of radio-labelled compounds such as ${ }^{51} \mathrm{Cr}$-EDTA can be used as 'reference methods' [4]. These methods, however, are time-consuming and expensive, and require special equipment, so they are only suitable for research or highly specialised clinical settings. Creatinine alone is insufficient for estimating GFR and leads to delays in detecting earlier stages of kidney failure [5]. Creatinine clearance determination involving timed urine collections may provide greater accuracy, but is inconvenient for patients to perform, time-consuming and not very practical for routine use. Moreover, inaccuracies may still arise if the specimens are under- or over-collected [6]. These problems have led to the development of serum creatinine-based equations for eGFR (eGFRcre), such as the CockcroftGault, the Modification of Diet in Renal Disease (MDRD) and the Chronic Kidney Disease Epidemiology Collaboration (CKD-EPI) equations [7-9]. Compared with the clearance method, these equations are simpler, less costly and easily available.

However, these creatinine-based equations have several limitations. The Cockcroft-Gault equation has not been reexpressed for use with standardised serum creatinine, and GFR estimates using the Cockcroft-Gault equation with standardised serum creatinine will generally be higher and less accurate than those with non-standardised creatinine [10]. Thus, most clinical laboratories now report GFR estimates using the MDRD equation. However, this prediction equation has not been tested extensively in persons with type 2 diabetes who receive insulin and in the elderly ( $>70$ years of age) [8]. The new CKD-EPI equation showed improved performance compared with the MDRD equation, but various studies of different populations were pooled in order to develop and validate the CKD-EPI equation, and relatively few participants were older than 70 years [9]. Moreover, only limited clinical information, especially on the type of diabetes, was supplied in the original study describing the CKD-EPI formula [9].

An alternative approach under investigation is the measurement of cystatin $\mathrm{C}$ concentration as a surrogate for GFR [11]. Cystatin $\mathrm{C}$ is a low molecular mass basic protein, which is filtered at the glomerulus and then completely reabsorbed and catabolised by tubular cells.
Recently, several cystatin C-based equations for GFR estimation (eGFRcys), based solely on serum cystatin C levels, have also been developed, and in some studies have been shown to be equal or superior to eGFRcre methods which require information on patient age, sex and ethnicity [11].

This study was designed to compare the performance of eGFRcys with that of eGFRcre (MDRD, CKD-EPI equations) in predicting the ${ }^{51} \mathrm{Cr}$-EDTA-measured GFR (mGFR) in type 2 diabetic patients with a broad range of renal function.

\section{Methods}

Participants and ethics In this cross-sectional study (ClinicalTrials.gov ID no. NCT01215994), 460 consecutive type 2 diabetic patients aged $65.0 \pm 10.0$ years $($ mean \pm SD) (216 men, 244 women) were recruited from our outpatient diabetic clinic. All participants were Europids. The study was approved by the local Ethics Committee and conducted in accordance with the Helsinki Declaration. Informed consent was obtained from every participant.

Analytical methods We used ${ }^{51} \mathrm{Cr}$-EDTA to measure mGFR with the slope-intercept technique, according to published guidelines [10]. In brief, blood samples were collected at 120 and $240 \mathrm{~min}$ after an intravenous injection of ${ }^{51} \mathrm{Cr}$ EDTA (3 mBq). A scintillation well counter (Cobra II; Packard, Meriden, CT, USA) was set to count plasma ${ }^{51} \mathrm{Cr}$ and the quadratic Brochner-Mortensen correction was applied in calculations [12]. In 12 participants, the mGFR value was $<30 \mathrm{ml} \mathrm{min}^{-1} 1.73 \mathrm{~m}^{-2}$. Due to the small sample,

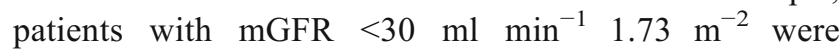
excluded from the study. In the end, 448 participants were enrolled (211 men, 237 women). The study population was divided into three groups according to mGFR (group 1: mGFR $\geq 90 \mathrm{ml} \mathrm{min}{ }^{-1} 1.73 \mathrm{~m}^{-2}$; group 2: mGFR 60$89 \mathrm{ml} \mathrm{min}^{-1} 1.73 \mathrm{~m}^{-2}$; group 3: mGFR $30-59 \mathrm{ml} \mathrm{min}^{-1}$ $1.73 \mathrm{~m}^{-2}$ ).

Serum creatinine and cystatin $\mathrm{C}$ measurements were performed with a chemistry analyser (Cobas Integra 400, Roche, Rotkreuz, Switzerland). Reagents were obtained from Roche Diagnostics (Mannheim, Germany). Serum creatinine was determined using the Jaffé Gen.2 method, which has been standardised against isotope dilution mass spectrometry (IDMS). The intra- and interassay CVs for creatinine were $1.4 \%$ and $3.1 \%$, respectively. Serum cystatin $\mathrm{C}$ was measured by an automated particle-enhanced immunoturbidimetric method (Tina-quant cystatin $\mathrm{C}$ assay; Roche). The intra- and interassay CVs for cystatin $\mathrm{C}$ were $1.2 \%$ and $2.7 \%$, respectively.

Estimation of renal function Blood samples for biochemical analyses were obtained on the day of the mGFR measurement. 
The eGFRcre and eGFRcys compared in this study [9, 13-22] are presented in Table 1. Details on all these equations are available in electronic supplementary material (ESM) Table 1. Previously published eGFRcys were developed using three different commercially available cystatin $\mathrm{C}$ assays: Dako (Dakocytomation, Glostrup, Denmark), Dade Behring (Siemens, Munich, Germany) and Gentian (Gentian, Moss, Norway). The Dade Behring assay is a particle-enhanced nephelometric immunoassay (PENIA), whereas the Gentian and Dako assays are particleenhanced turbidimetric immunoassays (PETIA). These three assays are known to give somewhat different results. Hansson et al. compared the Tina-quant cystatin $\mathrm{C}$ assay (PETIA) (Roche) that we used with the Dade Behring, Dako and Gentian assays, and established the linear relationships between them [23]. As past studies have used cystatin $\mathrm{C}$ levels measured using different methods, we attempted to standardise the cystatin $\mathrm{C}$ measurements used in these studies. We did this by calibrating cystatin $\mathrm{C}$ levels that were measured using the Dade Behring, DAKO or Gentian methods according to the regression equations developed by Hansson as follows: (1) cystatin $\mathrm{C}_{\text {Dade Behring } / \text { Siemens }}=\left(\right.$ cystatin $\left.\mathrm{C}_{\text {Roche }}-0.21\right) / 0.904$; (2) cystatin $\mathrm{C}_{\text {Dako }}=\left(\right.$ cystatin $\left.\mathrm{C}_{\text {Roche }}+0.099\right) / 0.993$; and (3) cystatin $\mathrm{C}_{\mathrm{Gentian}}=\left(\right.$ cystatin $\left.\mathrm{C}_{\text {Roche }}-0.14\right) / 0.954$ [23].

Statistical analysis Statistical analysis was performed in the entire population and in each group separately. Performance of each eGFR equation was assessed in terms of bias (mean difference between eGFR and mGFR), precision (SD of bias) and accuracy (proportion of eGFR results within 10\% and $30 \%$ of mGFR). Quantitative variables are presented as mean \pm 1 SD. Initially, eGFR results were compared with
mGFR using the paired $t$ test. A Pearson correlation coefficient and the standard multiple regression analysis were used to explore the relationship between the bias of the MDRD equation and a number of variables. The bias of the MDRD equation was compared with the bias of the other eGFR equations using the paired $t$ test. The precision of the MDRD equation was compared with the precision of the other eGFR equations using Levene's test for equality of variance. Finally, the accuracy of the MDRD equation was compared with the accuracy of the other eGFR equations using McNemar's test. The sensitivity and specificity of all equations for detecting mGFR $<60$ and $<90 \mathrm{ml} \mathrm{min}^{-1} 1.73 \mathrm{~m}^{-2}$ were assessed from non-parametric receiver operating characteristic curves. AUCs were calculated and compared. The AUC, the sensitivity and the specificity are presented with $95 \%$ CIs. These calculations were performed with SPSS, version 17.0 (SPSS, Chicago, IL, USA) and MedCalc, version 15.5.1 (www.medcalc.org, accessed 2 May 2011). A value of $p<0.01$ was considered to indicate statistical significance.

\section{Results}

The characteristics of the 448 diabetic patients are shown in Table 2. The performance of the eGFRcre and eGFRcys is presented in Table 3. These tables present only the eGFRcre (MDRD, CKD-EPI) and the calibrated eGFRcys with the highest performance (Tan-C equation). Details on the performance of all cystatin $\mathrm{C}$ equations (uncalibrated and calibrated) are available in the ESM text and in ESM Tables 2 and 3. The mean difference between mGFR and all eGFR equations (bias) was statistically significant (Table 2).
Table 1 Creatinine- and cystatin C-based equations for estimating GFR

Cystatin $\mathrm{C}$ is in $\mathrm{mg} / \mathrm{l}$

Scr, serum creatinine in $\mu \mathrm{mol} / 1$

\begin{tabular}{|c|c|}
\hline Equation & Name \\
\hline $175 \times(\mathrm{Scr} / 88.4)^{-1.154} \times$ age $^{-0.203}(\times 0.742$ if female $)$ & MDRD [13] \\
\hline $144 \times(\mathrm{Scr} / 62)^{-0.329} \times(0.993)^{\mathrm{Age}}$, if female and Scr $\leq 62 \mu \mathrm{mol} / 1$ & CKD-EPI [9] \\
\hline $144 \times(\mathrm{Scr} / 62)^{-1.209} \times(0.993)^{\text {Age }}$, if female and Scr $>62 \mu \mathrm{mol} / 1$ & CKD-EPI [9] \\
\hline $141 \times(\mathrm{Scr} / 80)^{-0.411} \times(0.993)^{\mathrm{Age}}$, if male and $\mathrm{Scr} \leq 80 \mu \mathrm{mol} / 1$ & CKD-EPI [9] \\
\hline $141 \times(\mathrm{Scr} / 80)^{-1.209} \times(0.993)^{\mathrm{Age}}$, if male and Scr $>80 \mu \mathrm{mol} / 1$ & CKD-EPI [9] \\
\hline 100/cystatin C & Perkins [14] \\
\hline $74.835 /$ cystatin $C^{1.333}$ & Arnal [15] \\
\hline $66.8 /$ cystatin $C^{1.30}$ & Rule [16] \\
\hline$(84.6 /$ cystatin $C)-3.2$ & MacIsaac [17] \\
\hline $127.7 \times$ cystatin $\mathrm{C}^{-1.17} \times \operatorname{age}^{-0.13}(\times 0.91$ if female $)$ & Stevens $[18]$ \\
\hline $177.6 \times(\text { creatinine } / 88.4)^{-0.65} \times$ cystatin $\mathrm{C}^{-0.57} \times$ age $^{-0.20}(\times 0.82$ if female $)$ & Stevens $[18]$ \\
\hline$(8.1 /$ cystatin $C)-6.87$ & Tan $[19]$ \\
\hline $86.49 \times$ cystatin $C^{-1.686}(\times 0.948$ if female $)$ & Grubb [20] \\
\hline$(100 /$ cystatin $C)-14$ & Tidman [21] \\
\hline $79.901 \times$ cystatin $\mathrm{C}^{-1.4389}$ & Flodin [22] \\
\hline
\end{tabular}


Table 2 Patient characteristics and eGFR data
Data are means $\pm \mathrm{SD}$, unless otherwise stated

${ }^{\mathrm{a}}$ In $\mathrm{ml} \mathrm{min}{ }^{-1} 1.73 \mathrm{~m}^{-2}$

${ }^{\mathrm{b}} p<0.01$ for the difference between mGFR and eGFR equations

\begin{tabular}{|c|c|c|c|c|}
\hline \multirow[t]{2}{*}{ Variable } & \multicolumn{4}{|l|}{$\mathrm{GFR}^{\mathrm{a}}$} \\
\hline & Total & $30-59$ & $60-89$ & $>90$ \\
\hline$n$ & 448 & 145 & 194 & 109 \\
\hline Men $(\%)$ & 47 & 45 & 45 & 52 \\
\hline Women $(\%)$ & 53 & 55 & 55 & 48 \\
\hline Age (years) & $65 \pm 10$ & $71 \pm 9$ & $66 \pm 9$ & $56 \pm 8$ \\
\hline Duration (years) & $11.5 \pm 9.0$ & $14.3 \pm 9.8$ & $11.7 \pm 8.5$ & $7.9 \pm 7.4$ \\
\hline BMI $\left(\mathrm{kg} / \mathrm{m}^{2}\right)$ & $31.1 \pm 10.1$ & $30.0 \pm 4.0$ & $32.4 \pm 13.9$ & $30.0 \pm 5.1$ \\
\hline \multicolumn{5}{|l|}{ Treatment } \\
\hline Oral hypoglycaemic agents $(\%)$ & 53 & 42 & 56 & 63 \\
\hline Insulin (\%) & 12 & 20 & 11 & 4 \\
\hline Both $(\%)$ & 35 & 38 & 33 & 33 \\
\hline Glucose (mmol/l) & $8.9 \pm 3.4$ & $8.7 \pm 3.6$ & $8.8 \pm 3.3$ & $9.4 \pm 3.4$ \\
\hline $\mathrm{HbA}_{1 \mathrm{c}} \%$ & $7.0 \pm 1.6$ & $7.0 \pm 1.5$ & $6.8 \pm 1.5$ & $7.3 \pm 1.8$ \\
\hline $\mathrm{HbA}_{1 \mathrm{c}}(\mathrm{mmol} / \mathrm{mol})$ & $53.0 \pm 17.0$ & $53.0 \pm 15.5$ & $50.8 \pm 15.5$ & $56.2 \pm 20.4$ \\
\hline Creatinine $(\mu \mathrm{mol} / \mathrm{l})$ & $79.5 \pm 26.5$ & $97.2 \pm 26.5$ & $70.7 \pm 8.8$ & $61.8 \pm 8.8$ \\
\hline Cystatin C (mg/l) & $1.1 \pm 0.4$ & $1.5 \pm 0.5$ & $1.0 \pm 0.3$ & $0.8 \pm 0.3$ \\
\hline $\mathrm{mGFR}^{\mathrm{a}}$ & $73.4 \pm 23.0$ & $48.1 \pm 8.1$ & $73.7 \pm 8.1$ & $104.2 \pm 11.5$ \\
\hline $\mathrm{MDRD}^{\mathrm{a}}$ & $80.7 \pm 24.6^{\mathrm{b}}$ & $56.0 \pm 13.0^{\mathrm{b}}$ & $82.9 \pm 13.6^{\mathrm{b}}$ & $108.2 \pm 18.5$ \\
\hline CKD-EPI ${ }^{\mathrm{a}}$ & $80.4 \pm 20.7^{b}$ & $57.6 \pm 13.9^{\mathrm{b}}$ & $84.6 \pm 11.8^{\mathrm{b}}$ & $101.9 \pm 8.7$ \\
\hline Tan- $\mathrm{C}^{\mathrm{a}}$ & $69.7 \pm 22.0^{\mathrm{b}}$ & $51.0 \pm 14.9$ & $72.8 \pm 15.8$ & $87.7 \pm 20.9^{\mathrm{b}}$ \\
\hline
\end{tabular}

The bias of the MDRD equation was significantly correlated with age $(r=0.135 ; p=0.01)$. There were no significant relationships between the MDRD equation bias and other variables (duration, sex, glucose-lowering therapy, BMI, $\mathrm{HbA}_{1 \mathrm{c}}$ ). In standard multiple regression analysis, age was an independent predictor of MDRD equation bias $(B=0.147$; $p=0.006$ ).

Calibration markedly worsened the performance of all eGFRcys based on the Dade Behring and Gentian assays, and improved the performance of the Grubb [20] and Tan [19] equations (eGFRcys), which are based on the Dako assay (ESM Table 3).
In the entire study population, the calibrated Tan-C equation (eGFRcys) was the least biased $\left(-3.5 \mathrm{ml} \mathrm{\textrm {min } ^ { - 1 }}\right.$ $1.73 \mathrm{~m}^{-2}$ ). On the other hand, the MDRD and CKD-EPI equations (eGFRcre) were the most precise (13.4 and $12.0 \mathrm{ml} \mathrm{min}^{-1} 1.73 \mathrm{~m}^{-2}$ respectively). The MDRD, CKDEPI and Tan-C equations demonstrated the same accuracy within $30 \%(78.8 \%, 80.7 \%$ and $78.8 \%$, respectively) and $10 \%$ (33.2\%, 38.0\% and $39.0 \%$ respectively).

In patients with mGFR between 30 and $89 \mathrm{ml} \mathrm{min}^{-1}$ $1.73 \mathrm{~m}^{-2}$, the Tan-C equation was the least biased. However, in patients with mGFR $\geq 90 \mathrm{ml} \mathrm{min}{ }^{-1} 1.73 \mathrm{~m}^{-2}$, the MDRD formula was less biased than the Tan-C equation. Compared

Table 3 Predictive performance of creatinine- and cystatin C-based formulae in the entire diabetic population and at different levels of renal function by GFR

\begin{tabular}{|c|c|c|c|c|c|c|c|c|c|c|c|c|c|c|c|c|}
\hline \multirow[t]{2}{*}{ Equation } & \multicolumn{4}{|l|}{ Total } & \multicolumn{4}{|c|}{ GFR $30-59 \mathrm{ml} \mathrm{min}-11.73 \mathrm{~m}^{-2}$} & \multicolumn{4}{|c|}{ GFR $60-89 \mathrm{ml} \mathrm{min}{ }^{-1} 1.73 \mathrm{~m}^{-2}$} & \multicolumn{4}{|c|}{ GFR $\geq 90 \mathrm{ml} \mathrm{min}-11.73 \mathrm{~m}^{-2}$} \\
\hline & B. & Pr. & & A. $10 \%$ & B. & Pr. & A. $30 \%$ & A. $10 \%$ & B. & Pr. & A. $30 \%$ & A. $10 \%$ & B. & Pr. & A. $30 \%$ & A. $10 \%$ \\
\hline MDRD & 7.5 & 13.4 & 78.8 & 33.2 & 7.5 & 9.5 & 69.3 & 26.3 & 9.4 & 12.6 & 77.9 & 33.7 & 4.1 & 17.8 & 92.2 & 37.8 \\
\hline CKD-EPI & 7.1 & 12.0 & 80.7 & 38.0 & $9.1^{\mathrm{b}}$ & 10.1 & 63.2 & 27.2 & $11.1^{\mathrm{b}}$ & $10.6^{\mathrm{a}}$ & 82.5 & 32.5 & $-2.1^{\mathrm{a}}$ & $11.4^{\mathrm{a}}$ & 100 & $61.1^{\mathrm{a}}$ \\
\hline Tan-C & $-3.5^{\mathrm{a}}$ & $18.0^{\mathrm{b}}$ & 78.8 & 39.0 & $2.9^{\mathrm{a}}$ & 12.5 & 73.0 & 31.3 & $-0.7^{\mathrm{a}}$ & 15.3 & 84.0 & 43.6 & $-16.1^{\mathrm{b}}$ & 21.4 & 77.4 & 40.9 \\
\hline
\end{tabular}

${ }^{\mathrm{a}} p<0.01$ for difference between MDRD and other equations, favouring other equations; ${ }^{\mathrm{b}} p<0.01$ for difference between MDRD and other equations, favouring MDRD

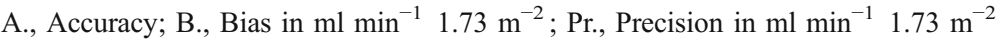


with the CKD-EPI equation, the MDRD equation was less biased in patients with mGFR $<90 \mathrm{ml} \mathrm{min}{ }^{-1} 1.73 \mathrm{~m}^{-2}$ and more biased in patients with $\mathrm{mGFR} \geq 90 \mathrm{ml} \mathrm{min}^{-1} 1.73 \mathrm{~m}^{-2}$.

In patients with $\mathrm{mGFR} \geq 60 \mathrm{ml} \mathrm{min}^{-1} 1.73 \mathrm{~m}^{-2}$, the CKD-EPI was the most precise equation. With regard to accuracy, in patients with mGFR $<90 \mathrm{ml} \mathrm{min}-1.73 \mathrm{~m}^{-2}$, the proportion of eGFR results within $10 \%$ and $30 \%$ of mGFR was the same when using the MDRD, CKD-EPI and Tan-C formulae. However, in patients with $\mathrm{mGFR} \geq 90 \mathrm{ml} \mathrm{min}^{-1}$ $1.73 \mathrm{~m}^{-2}$, the CKD-EPI formula was more accurate.

The AUC was higher with eGFRcre (CKD-EPI and MDRD) than with the Tan-C equation for diagnosis of mild (mGFR $<90 \mathrm{ml} \mathrm{min}{ }^{-1} 1.73 \mathrm{~m}^{-2}$ ) and moderate (mGFR $<60 \mathrm{ml} \mathrm{min}{ }^{-1} 1.73 \mathrm{~m}^{-2}$ ) chronic renal disease (Table 4, Fig. 1). The AUC, sensitivity and specificity of all eGFRcys are available in ESM Table 4 and ESM Fig. 1.

\section{Discussion}

To our knowledge, this is the first study comparing eGFRcre and eGFRcys with mGFR in a sizable group of participants consisting exclusively of type 2 diabetic patients with a broad range of renal function. We found no evidence that equations based on cystatin $\mathrm{C}$ alone or in combination with creatinine provide better GFR estimates than the commonly used MDRD and CKD-EPI equations in type 2 diabetic patients with mild and moderate chronic kidney disease, or in type 2 diabetic patients with normal renal function. Our results are in accordance with a recent study of 1621 middle-aged patients without self-reported cardiovascular disease or diabetes mellitus [24].

Variation in creatinine assays is a great concern, adding systematic errors to eGFR. IDMS is considered the gold standard for establishing true creatinine concentration [5]. Thus, creatinine values must be traceable to an IDMS reference value for creatinine measurements to be comparable regardless of method or laboratory used. Concerning the eGFRcre, the CKD-EPI equation was developed for use only with standardised creatinine values and the MDRD equation has been re-expressed for standardised serum creatinine [13], while the Cockcroft-Gault equation has not. Therefore, the eGFR using the Cockcroft-Gault equation with standardised serum creatinine is generally higher and less accurate than with non-standardised creatinine [10]. Following the latest recommendations, serum creatinine was measured by an IDMS traceable Jaffé method in our study [13, 25]. Consequently, we used the CKD-EPI equation and the revised MDRD equation for eGFR, but did not use the Cockcroft-Gault equation.

We found that the MDRD and CKD-EPI equations overestimate the mGFR $(10.0 \%$ and $9.5 \%$, respectively). This result is not supported by some previous studies. It has been extensively demonstrated that the MDRD equation, although reasonably accurate when evaluating the kidney function of patients with chronic kidney disease [26, 27], tends to underestimate the GFR in participants with normal or near-normal renal function [26, 27], as well as in diabetic patients [28], especially those with obesity [29]. This systemic underestimation has been ascribed to the fact that the MDRD equation was developed in chronic kidney disease patients. One possible explanation of our results could be the advanced age of our patients $(52.8 \%$ of patients were 65 to 80 years old, while $3.7 \%$ were over 80 years old). Indeed, in our study, the bias of the MDRD formula was related to patient age, and this may be partly ascribed to the fact that, in the original MDRD study population, the age limit was 70 years [8]. Previous studies have also shown that the MDRD equation overestimates renal function as age increases [26, 30, 31] and that this overestimation does not become apparent until 65 years of age. The overestimation of renal function by the MDRD equation increases from $12 \%$ to $26 \%$ to $69 \%$ across the $<65$, 65-80 and $>80$ years age groups, respectively [31].

Several factors may contribute to the insufficient performance of most of the eGFRcys in our study group. It has been demonstrated that cystatin $\mathrm{C}$ is affected by factors other than GFR [32]. Thus, in patients with chronic kidney disease, cystatin $\mathrm{C}$ was $4.3 \%$ lower for every 20 years of age and $9.2 \%$ lower in women. In addition, diabetes was associated with $8.5 \%$ higher levels of cystatin C. Higher BMI, C-reactive protein and leucocyte count, and

Table 4 Diagnosis of GFR by creatinine- and cystatin C-based equations for estimating GFR

\begin{tabular}{|c|c|c|c|c|c|c|}
\hline \multirow[b]{2}{*}{ Equation } & \multicolumn{3}{|c|}{ GFR $<60 \mathrm{ml} \mathrm{min}{ }^{-1} 1.73 \mathrm{~m}^{-2}$} & \multicolumn{3}{|c|}{ GFR $<90 \mathrm{ml} \mathrm{min}{ }^{-1} 1.73 \mathrm{~m}^{-2}$} \\
\hline & Sensitivity & Specificity & AUC $(95 \%$ CI $)$ & Sensitivity & Specificity & AUC $(95 \% \mathrm{CI})$ \\
\hline MDRD & $86.5(78.7,92.2)$ & $89.5(85.0,93.0)$ & $0.947(0.917,0.968)$ & $73.9(68.2,79.0)$ & $94.8(88.3,98.3)$ & $0.920(0.887,0.947)$ \\
\hline CKD-EPI & $91.0(84.1,95.6)$ & $88.3(83.6,92.0)$ & $0.952(0.924,0.972)$ & $84.3(79.4,88.5)$ & $91.7(84.2,96.3)$ & $0.937(0.906,0.960)$ \\
\hline Tan-C & $81.2(72.8,88.0)$ & $79.8(74.3,84.5)$ & $0.868(0.828,0.902)^{\mathrm{a}}$ & $85.2(80.4,89.2)$ & $67.0(56.6,76.4)$ & $0.823(0.799,0.862)^{\mathrm{a}}$ \\
\hline
\end{tabular}

Values are per cent $(95 \% \mathrm{CI})$, unless otherwise indicated

${ }^{\mathrm{a}} p<0.01$ for difference between MDRD and other equations, favouring MDRD 
Fig. 1 a AUC of CKD-EPI

(continuous line), MDRD

(dashed line) and Tan-C

(dotted and dashed line) equa-

tions for the diagnosis of

moderate chronic kidney disease

(GFR $<60 \mathrm{ml} \mathrm{min}^{-1} 1.73 \mathrm{~m}^{-2}$ ).

b AUC of CKD-EPI, MDRD

and Tan-C equations for

the diagnosis of mild

chronic kidney disease

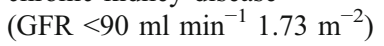
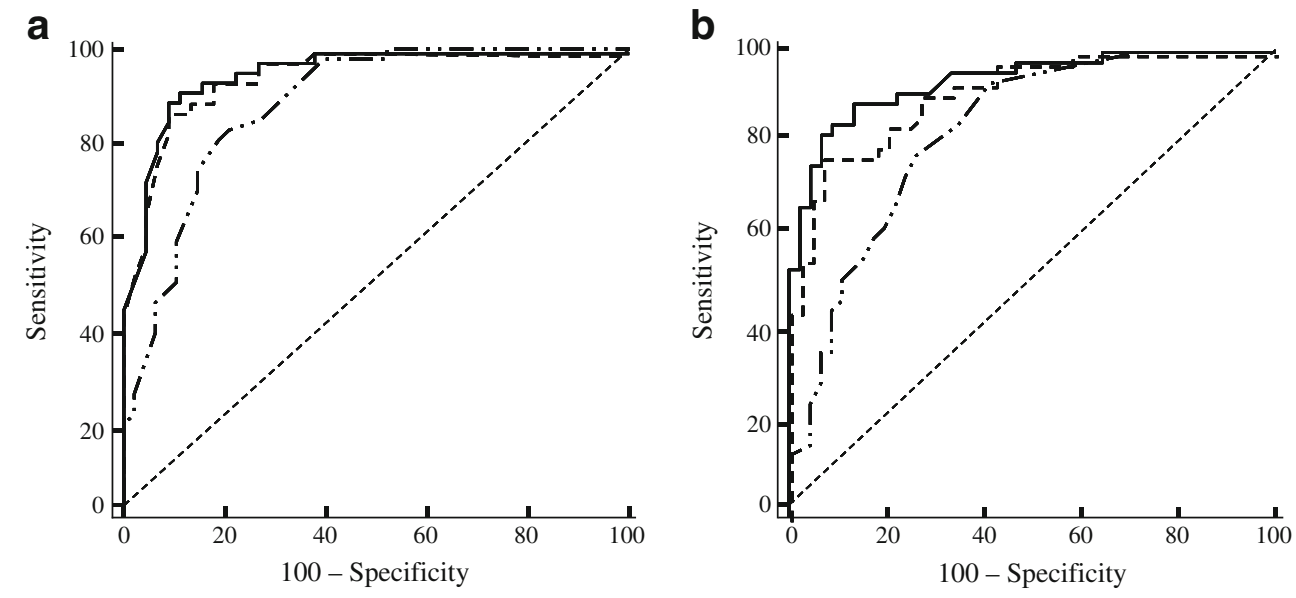

lower serum albumin were also associated with higher levels of cystatin C [32]. As most eGFRcys were developed in populations with chronic kidney disease, the influence of non-GFR factors on plasma cystatin $\mathrm{C}$ may differ between those patients and type 2 diabetic patients. Thus, the application of these eGFRcys in elderly, obese patients with type 2 diabetes seems to lead to an incorrect estimation of GFR. In addition, there is no standardisation between assays and laboratories for cystatin C [33]. We used published results to calibrate our measurements of cystatin $\mathrm{C}$ to other methods [23], but this calibration worsened the results for almost all eGFRcys. By leading to the precise cystatin $\mathrm{C}$ levels that should be used according to each eGFRcys equation, our calibration seems to have revealed the true extent of the insufficient performance of these equations. According to recent studies, a downward shift in calibration for the Siemens cystatin C method occurred between 2006 and 2010 [34, 35]. Therefore, eGFRcys that were derived from results obtained from older lots of reagent and calibrator cannot be used with the current Siemens method. These observations emphasise the need for an international cystatin $\mathrm{C}$ reference value and may partly explain the results of our study. For the time being, the lack of standardisation is a serious obstacle for routine use of eGFRcys. If this obstacle could be overcome, eGFR levels based solely on cystatin C (without the need for correction for age, sex or ethnicity) could provide a more accurate way of estimating GFR than creatinine-based formulae, which require information on patient age, sex and ethnicity.

Compared with eGFRcys, the eGFRcre were better at predicting the stage of CKD. The ability of the MDRD and CKD-EPI equations to detect mild and moderate chronic renal disease is the same. However, the CKD-EPI equation seems to be more reliable for eGFR in patients with normal renal function. This result was expected, because the CKDEPI equation was developed by analysing individuals with and without renal function loss [9].
One limitation of our study could be that serum creatinine was determined using the Jaffé method. Plasma glucose is a well-known interfering factor in the measurement of creatinine by the Jaffé reaction [36]. However, this analytical error is only observed with glucose levels above $17 \mathrm{mmol} / \mathrm{l}$, and our patients had levels well below these values.

Previous studies have shown that the different reference methods used to measure GFR can give different results $[4,37]$. Thus, we cannot know whether our results would have been exactly the same if we had used another reference method instead of ${ }^{51} \mathrm{Cr}$-EDTA.

Since our study population consisted of whites only, we were not able to study the effect of ethnicity. In addition, we were not able to study the performance of eGFR equations in patients with mGFR $<30 \mathrm{ml} \mathrm{min}^{-1} 1.73 \mathrm{~m}^{-2}$, due to the small number of such patients in the population studied.

One strength of our findings is the homogeneity of the study cohort. All participants had type 2 diabetes and both sexes were almost equally represented. Participants were being treated with all kinds of glucose-lowering therapies (pills, insulin or both). Most of them were obese and had good glycaemic control.

We conclude that, in patients with type 2 diabetes mellitus, published eGFRcys alone, or combined with creatinine, do not currently provide better eGFR values than the eGFRcre, MDRD and CKD-EPI equations. At present, compared with eGFRcys, the eGFRcre are better at predicting the stage of CKD. In addition, the CKD-EPI equation seems to be the best one for eGFR in type 2 diabetic patients with normal renal function.

However, it should be noted that whatever the eGFR method used, less than $40 \%$ of the eGFR values were within a $10 \%$ range of the actual mGFR. This result emphasises the lack of accuracy of the eGFR equations. Using an eGFR equation has improved the assessment of renal function in daily practice, but is still only a step 
towards more reliability, and does not enable a final conclusion on renal function. The accuracy of current GFR estimation procedures is therefore certainly open to improvement.

Contribution statement FI and TD designed and performed the research, and wrote the manuscript. AN performed research. DG designed the research and reviewed/edited the manuscript. All authors contributed to the analysis and interpretation of data and the drafting of the manuscript. All authors approved the final version to be published.

Duality of interest The authors declare that there is no duality of interest associated with this manuscript.

\section{References}

1. Williams ME (2010) Diabetic CKD/ESRD 2010: a progress report? Semin Dial 23:129-133

2. KDOQI (2007) KDOQI clinical practice guidelines and clinical practice recommendations for diabetes and chronic kidney disease. Am J Kidney Dis 49:S12-S154

3. American Diabetes Association (2011) Standards of medical care in diabetes - 2011. Diabetes Care 34:S11-S61

4. Stevens LA, Levey AS (2009) Measured GFR as a confirmatory test for estimated GFR. J Am Soc Nephrol 20:2305-2313

5. Myers GL, Miller WG, Coresh J et al (2006) Recommendations for improving serum creatinine measurement: a report from the laboratory working group of the national kidney disease education program. Clin Chem 52:5-18

6. Swan SK (1997) The search continues - an ideal marker of GFR. Clin Chem 43:913-914

7. Cockcroft DW, Gault MH (1976) Prediction of creatinine clearance from serum creatinine. Nephron 16:31-41

8. Levey AS, Bosch JP, Lewis JB, Greene T, Rogers N, Roth D (1999) A more accurate method to estimate glomerular filtration rate from serum creatinine: a new prediction equation. Ann Intern Med 130:461-470

9. Levey AS, Stevens LA, Schmid CH et al (2009) A new equation to estimate glomerular filtration rate. Ann Intern Med 150:604612

10. Stevens LA, Manzi J, Levey AS et al (2007) Impact of creatinine calibration on performance of GFR estimating equations in a pooled individual patient database. Am J Kidney Dis 50:21-35

11. Herget-Rosenthal S, Bökenkamp A, Hofmann W (2007) How to estimate GFR-serum creatinine, serum cystatin $\mathrm{C}$ or equations? Clin Biochem 40:153-161

12. Fleming JS, Zivanovic MA, Blake GM, Burniston M, Cosgriff PS (2004) Guidelines for the measurement of glomerular filtration rate using plasma sampling. Nucl Med Commun 25:759-769

13. Levey AS, Coresh J, Greene $T$ et al (2007) Expressing the Modification of Diet in Renal Disease study equation for estimating glomerular filtration rate with standardized serum creatinine values. Clin Chem 53:766-772

14. Perkins BA, Nelson RG, Ostrander BEP et al (2005) Detection of renal function decline in patients with diabetes and normal or elevated GFR by serial measurements of serum cystatin C concentration: results of a 4-year follow-up study. J Am Soc Nephrol 16:1404-1412
15. Beauvieux MC, Le Moigne F, Lasseur C et al (2007) New predictive equations improve monitoring of kidney function in patients with diabetes. Diabetes Care 30:1988-1994

16. Rule AD, Bergstralh EJ, Slezak JM, Bergert J, Larson TS (2006) Glomerular filtration rate estimated by cystatin $\mathrm{C}$ among different clinical presentations. Kidney Int 69:399-405

17. MacIsaac RJ, Tsalamandris C, Thomas MC et al (2006) Estimating glomerular filtration rate in diabetes: a comparison of cystatin C- and creatinine-based methods. Diabetologia 49:16861689

18. Stevens LA, Coresh J, Schmid CH et al (2008) Estimating GFR using serum cystatin $\mathrm{C}$ alone and in combination with serum creatinine: a pooled analysis of 3418 individuals with CKD. Am J Kidney Dis 51:395-406

19. Tan GD, Lewis AV, James TJ, Altmann P, Taylor RP, Levy JC (2002) Clinical usefulness of cystatin $C$ for the estimation of glomerular filtration rate in type 1 diabetes. Reproducibility and accuracy compared with standard measures and iohexol clearance Diabetes Care 25:2004-2009

20. Grubb A, Nyman U, Björk J et al (2005) Simple cystatin Cbased prediction equations for glomerular filtration rate compared with the Modification of Diet in Renal Disease prediction equation for adults and the Schwartz and the CounahanBarratt prediction equations for children. Clin Chem 51:1420 1431

21. Tidman M, Sjöström P, Jones I (2008) A comparison of GFR estimating formulae based upon s-cystatin $\mathrm{C}$ and s-creatinine and a combination of the two. Nephrol Dial Transplant 23:154160

22. Flodin M, Jonsson AS, Hansson LO, Danielsson LA, Larsson A (2007) Evaluation of Gentian cystatin C reagent on Abbott Ci8200 and calculation of glomerular filtration rate expressed in $\mathrm{mL} / \mathrm{min} / 1.73 \mathrm{~m} 2$ from the cystatin C values in $\mathrm{mg} / \mathrm{L}$. Scand J Clin Lab Invest 67:560-567

23. Hansson LO, Grubb A, Lidén A et al (2010) Performance evaluation of a turbidimetric cystatin $\mathrm{C}$ assay on different highthroughput platforms. Scand J Clin Lab Invest 70:347-353

24. Eriksen BO, Mathisen UD, Melsom T et al (2010) Cystatin C is not a better estimator of GFR than plasma creatinine in the general population. Kidney Int 78:1305-1311

25. Levey AS, Coresh J, Greene T et al (2006) Using standardized serum creatinine values in the Modification of Diet in Renal Disease study equation for estimating glomerular filtration rate. Ann Intern Med 145:247-254

26. Stevens LA, Coresh J, Feldman HI et al (2007) Evaluation of the Modification of Diet in Renal Disease study equation in a large diverse population. J Am Soc Nephrol 18:2749-2757

27. Froissart M, Rossert J, Jacquot C, Paillard M, Houillier P (2005) Predictive performance of the Modification of Diet in Renal Disease and Cockcroft-Gault equations for estimating renal function. J Am Soc Nephrol 16:763-773

28. Chudleigh RA, Ollerton RL, Dunseath G et al (2008) Performance of the revised ' 175 ' Modification of Diet in Renal Disease equation in patients with type 2 diabetes. Diabetologia 51:17141718

29. Nair S, Mishra V, Hayden K et al (2011) The four-variable Modification of Diet in Renal Disease formula underestimates glomerular filtration rate in obese type 2 diabetic individuals with chronic kidney disease. Diabetologia 54:1304-1307

30. Björk J, Bäck SE, Sterner G et al (2007) Prediction of relative glomerular filtration rate in adults: new improved equations based on Swedish Caucasians and standardized plasma-creatinine assays. Scand J Clin Lab Invest 67:678-95

31. Roberts GW, Ibsen PM, Schiøler CT (2009) Modified Diet in Renal Disease method overestimates renal function in selected elderly patients. Age and Ageing 38:698-703 
32. Stevens LA, Schmid CH, Greene T et al (2009) Factors other than glomerular filtration rate affect serum cystatin C levels. Kidney Int 75:652-660

33. White CA, Rule AD, Collier CP et al (2011) The impact of interlaboratory differences in cystatin $\mathrm{C}$ assay measurement on glomerular filtration rate estimation. Clin J Am Soc Nephrol. doi:10.2215/CJN.00130111

34. Maahs DM, Jalal D, McFann K, Rewers M, Snell-Bergeon JK (2011) Systematic shifts in cystatin C between 2006 and 2010. Clin J Am Soc Nephrol 6:1952-1955
35. Larsson A, Hansson LO, Flodin M, Katz R, Shlipak MG (2011) Calibration of the Siemens cystatin $\mathrm{C}$ immunoassay has changed over time. Clin Chem 57:777-778

36. Husdan H, Rapaport A (1967) Estimation of creatinine by Jaffé reaction: a comparison of three methods. Clin Chem 14:222-238

37. Dai SS, Yasuda Y, Zhang CL, Horio M, Zuo L, Wang HY (2011) Evaluation of GFR measurement method as an explanation for differences among GFR estimation equations. Am J Kidney Dis $58: 496-498$ 